Research Paper:

\title{
The Effectiveness of Pilates Training and Vitamin D Intake on the hs-CRP and TSH in Overweight Men
}

\author{
Fatemeh Ebrahemi Rokni $^{1}$ (D), Masoumeh Habibian ${ }^{1^{*}}$ (D), Saqqa Farajtabar Behrestaq ${ }^{1}$ (D)
}

1. Department of Physical Education and Sports Sciences, Qaemshahar Branch, Islamic Azad University, Qaemshahar, Iran.

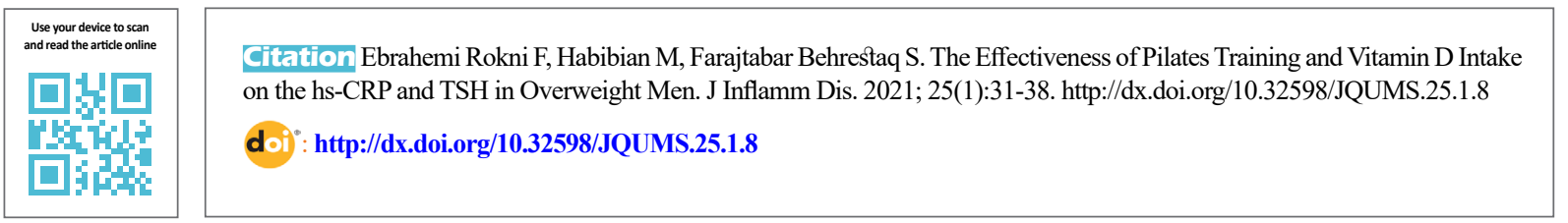

\section{(c) (1) (s)}

Article info:

Received: 31 Dec 2020

Accepted: 09 Feb 2021

Publish: 01 Apr 2021

Keywords:

C-reactive protein, Overweight, Pilates training, Thyrotropin, Vitamin D

\section{ABSTRACT}

Background: Vitamin D deficiency is known as a risk factor for various diseases and plays an important role in regulating systemic inflammation and thyroid function.

Objective: The study was done to survey the effectiveness of Pilates training and vitamin D intake on serum high-sensitivity C-reactive protein (hs-CRP) and Thyroid-Stimulating Hormone (TSH) levels in overweight men.

Methods: This clinical trial was conducted on 50 overweight men aged 45-55 years. Subjects were selected through available sampling and randomly assigned to the Pilates training, Pilates training with vitamin $\mathrm{D}$, vitamin $\mathrm{D}$, and control groups. The Pilates training was performed for eight weeks with the intensity of $50 \%-75 \%$ of reserve heart rate in 3 sessions/week. The supplement groups received 50000IU vitamin D weekly. The levels of hs-CRP and TSH were measured at first and eighth weeks after interventions. The data were analyzed by paired t-test and one-way ANOVA $(\mathrm{P}<0.05)$.

Findings: The results showed that $60 \%$ and $40 \%$ of the subjects had a vitamin D deficiency and insufficiency, respectively. Also, eight weeks of Pilates training, vitamin D intake, and the combined intervention resulted in a significant decrease in hs-CRP and TSH levels $(\mathrm{P}<0.05)$. Also, the combined intervention was associated with a stronger effect on the reduction of these factors compared with two other interventions $(\mathrm{P}<0.05)$.

Conclusion: It seems that abnormal levels of vitamin D are common in overweight men and vitamin D intake, Pilates training, and the combination can improve thyroid function and systemic inflammation in overweight men with abnormal vitamin D status. However, the combined intervention is associated with stronger effects.

\footnotetext{
* Corresponding Author:

Masoumeh Habibian

Address: Department of Physical Education and Sports Sciences, Qaemshahar Branch, Islamic Azad University, Qaemshahar, Iran.

Phone: +98 (11) 42155025

E-mail: habibian_m@yahoo.com
} 


\section{Introduction}

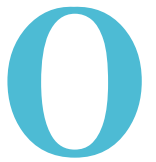

verweight and obesity are major health problems in developed countries that may be associated with low-grade inflammation in white adipose tissue [1]. In obese individuals, macrophage filtration in white adipose tissue is associated with increased local production of proinflammatory mediators, which in turn increases the acute-phase response and chronic inflammation [2]. On the other hand, vitamin D deficiency is also known as a risk factor for various diseases and plays an important role in modulating the immune system by enhancing the innate immune response and inhibitory action on the acquired immune system [3]. Thyroid hormones induce metabolic activity in most tissues and increase the basal metabolic rate in the body. Hypothyroidism is associated with weight gain, which can often lead to various diseases and obesity and affect the body's metabolism [4]. The synthesis and secretion of thyroid hormones are regulated by a negative feedback system involving the hypothalamic axis and pituitary and thyroid glands [5]. Thyrotropin-stimulating hormone secreted by the hypothalamus stimulates the anterior pituitary gland to release thyrotropin or Thyroid-Stimulating Hormone (TSH).

Vitamin D directly affects the pituitary gland, including the hypothalamic-pituitary-thyroid axis. The seasonal variability of serum TSH concentration in euthyroid subjects and a negative correlation between TSH levels and vitamin D status have been reported by Bansal et al. [6]. Also, the low levels of vitamin $\mathrm{D}$ in patients with hypothyroidism may be due to poor absorption of vitamin $\mathrm{D}$ from the intestine and the body may not activate vitamin D properly [7]. On the other hand, vitamin D deficiency increases inflammation, which is associated with cardiovascular and metabolic risks [8].

In addition, recent numerous studies have demonstrated the negative association of vitamin $\mathrm{D}$ and various inflammation biomarkers, such as high-sensitive C-reactive protein (hs-CRP) [9]. Liefaard et al. [10] have shown that higher levels of vitamin D were associated with lower levels of CRP. CRP is synthesized in the liver, and adipose tissue produces many pro-inflammatory cytokines, such as Tumour Necrosis Factor- $\alpha$ (TNF- $\alpha$ ) and Interleukin-6 (IL-6), which are important factors in its synthesis. Determination of the hs-CRP level is used to predict the risk of diabetes, ischemic heart disease, and cardiovascular events in healthy obese individuals [11]. Yarparvar et al. [8] found a negative correlation between the serum vitamin D level and hs-CRP in both positive- and negativehsCRP adolescents. However, higher levels of TSH and
hsCRP and their positive association have been reported in people with subclinical hypothyroidism [10].

Lifestyle changes, including regular physical activity, have been suggested as strategies to combat obesity and improve health problems in the world. Importantly, physical activity helps maintain a healthy weight or lose excess weight. Even light exercise, such as walking, swimming, or yoga can improve thyroid function through better glandular perfusion and stimulating tissue sensitivity to THS [6]. The results of a meta-analysis of 83 studies of randomized and non-randomized controlled trials showed that exercise training was associated with a decrease in CRP levels regardless of the age or sex of the individual, and greater improvements in CRP level occurred with a decrease in Body Mass Index (BMI) or fat percentage and weight loss [12].

Pilates may be one of the most attractive fitness training suitable for all people. This exercise can release the stress of the mind and improve muscle strength and flexibility as well as blood circulation and cardiopulmonary function [13]. However, other studies have reported that exercise is not effective on TSH and hsCRP levels of healthy inactive individuals $[13,14]$. The results reported about the association of thyroid function and BMI are inconsistent. Some researchers believe that even small changes in TSH levels can affect BMI profiles, [15] while other studies have shown no correlation between normal thyroid status and BMI [16]. In addition, moderate-intensity aerobic exercise is associated with the best results in improving TSH [6] and weekly intake of vitamin $\mathrm{D}$ has a positive effect on people with autoimmune thyroid disorders [17]. Therefore, due to the high prevalence of vitamin D deficiency or thyroid dysfunction, low intake of vitamin D with diet, and the development of a sedentary lifestyle in current societies, it seems necessary to conduct further studies on low-risk nonpharmacological methods. In this study, we investigated the effectiveness of regular Pilates exercises and vitamin D intake on CRP and hsCRP levels in overweight men.

\section{Materials and Methods}

The present quasi-experimental research was conducted with a pre-test and post-test design and a control group in 2019 on overweight (BMI and 25 to $29 \mathrm{~kg} / \mathrm{m}^{2}$ ) men aged $45-55$ years. The sample size was estimated to be 48 using G-Power software and considering the test power of 0.8 , alpha of 0.05 , and the effect size of 0.5 (12 people in each group) that with more caution, 13 people were considered for each group [18]. In the first step, from the volunteers who were enrolled in the 
sports clubs, 56 volunteers were selected using accessible and purposeful sampling, and then, the subjects were randomly assigned to the Pilates training, Pilates training+vitamin $\mathrm{D}$, vitamin $\mathrm{D}$, and control groups.

Inclusion criteria included being overweight, ability to perform exercise training, and not taking vitamin D supplements for the past six months. Exclusion criteria were also having diseases, such as diabetes mellitus, hypertension, and cardiovascular and inflammatory diseases), not taking vitamin $\mathrm{D}$ during the protocol, not doing Pilates exercises for three consecutive sessions, using any special medication or supplement, and smoking. Two subjects were excluded during the intervention; in the control group, one person took a supplement and one in the Pilates group did not participate in regular exercise.

This study protocol was approved by the Ethics Committee of Islamic Azad University, Babol Branch (Code: IR.IAU.BABOL.REC.1398.088) and registered a the Iranian Registry of Clinical Trial, and written informed consent was obtained from all participants.

The weight and height of the subjects were measured with standard and calibrated scales to the nearest $0.1 \mathrm{~kg}$ and $0.5 \mathrm{~cm}$, respectively. BMI was calculated as weight (in $\mathrm{kg}$ ) divided by height (in meters) squared.

\section{Pilates exercise protocol}

One week before the start of the study, the subjects were give explaination about the study process. The subjects in the Pilates and Pilates+vitamin D groups performed Pilates training for 60-75 minutes, 3 times a week for 8 weeks. The exercise program for each session included warm-up (10 minutes), basic Pilates training, and cooling-down (5 minutes).

The exercises started with low intensity and gradually increased, and included advanced stretching movements, strength, balance, flexibility, and neuromuscular coordination with a focus on the large muscles of the upper and lower limbs and in three positions: standing, sitting, and lying down.

Warm-up exercises included some postures, such as standing upright, respecting Pilates and breathing, stretching the opposite arm and leg in a quadruped position, lying on the back and forth on the vertebrae, capping the lumbar arch and folding the legs, standing cat, and vertebrae. Getting to the vertebrae in a quadruped position, rotating the arms and the neck, and cooling exercises and also movements, such as spinal stretch- ing, spinal screwing, back stretching, needle-to-thread movement, prostration, Pilates lateral breathing were also included and were done with an emphasis on proper inhalation and exhalation.

Basic exercises included shoulder bridge, single-leg stretching, stretching both legs, single-legged stretching with upper body screws, hundred movements, circling with one leg, raising single-legged from side to side, lying on the side-lying down, Cobra, Dart, and star, which started with an intensity of 50 to $55 \%$ of the reserve heart rate, one set and 10 repetitions in the first week, and continued with an intensity of 65 to $70 \%$ of the reserve heart rate, 4 sets with 12 repetitions (with a gradual increase of $5 \%$ intensity training, one set and 2 repeats every two weeks) in the eighth week [18]. The subjects' reserve heart rate was determined using the Karonen method and was monitored using a polar heart rate monitor during exercise. The maximum heart rate of the participants was calculated by subtracting the age from 220 .

\section{Supplementation}

The vitamin D and Pilates + vitamin D groups received $50,000 \mathrm{IU}$ vitamin $\mathrm{D}$ and the control group consumed oral paraffin for 8 weeks in a single-blind manner once per week. Both vitamin D and oral paraffin capsules had similar shapes, colors, and sizes, and were purchased from Zahravi Pharmaceutical Company, Tehran, Iran [18, 13].

Also, the daily caloric intake of individuals was calculated and during a meeting with each subject, dietary counseling was performed to follow the same diet to maintain weight. Subjects were advised to follow their normal diet during the study period (especially in the pre-blood sampling stages).

\section{Biochemical tests}

After overnight fasting, blood samples were collected from all participants, and the serum was separated by centrifuge and stored at $-80^{\circ} \mathrm{C}$. Circulating concentrations of 25-hydroxyvitamin $\mathrm{D}(25(\mathrm{OH}) \mathrm{D})$, as an indicator of vitamin $\mathrm{D}$ status, were determined. The normal range of serum $25(\mathrm{OH}) \mathrm{D}$ levels is $30-50 \mathrm{ng} / \mathrm{ml}$, while Vitamin D insufficiency is defined as serum levels of 20-29 $\mathrm{ng} / \mathrm{ml}$ and the levels below 20 and $10 \mathrm{ng} / \mathrm{ml}$ represent insufficiency and deficiency, respectively $[7,18]$.

The level of 25-hydroxyvitamin D (25-hydroxyvitamin D kit, Euroimmun, Luebeck, Germany) and hs-CRP (hs-CRP kit, Parsazmoon, Tehran, Iran) were measured using the ELISA method according to the manufacturer's 
instructions. TSH was measured using the Chemiluminescence immunoassay method and a commercial kit (DiaSorin, co. Italy).

\section{Statistical analysis}

The normal distribution of data and homogeneity of variances were investigated by Shapiro-Wilk and Levene's tests, respectively. The Cohen's d effect size was calculated to interpret the significant differences between groups. In general, $\leq 0.20$ is a small effect size, 0.50 is moderate effect size, and $\geq 0.80$ is a large effect size. In addition, paired t-test was used to examine the changes within the group and a One-way Analysis of Variance (ANOVA) was used to compare the percentage of changes in mean variables between the groups. When a difference was detected in the ANOVA model, the significant differences were determined using the Tukey post hoc test. All statistical analyses were conducted using SPSS v. 21 (SPSS Inc., Chicago, IL, USA) and results were statistically significant at $\mathrm{P}<0.05$.

\section{Results}

Baseline anthropometric characteristics and levels of 25-hydroxyvitamin D of the subjects are displayed in Table 1. In brief, based on the results of Shapiro-Wilk and one-way analysis of variance tests, there were no significant differences between general characteristic and 25-hydroxyvitamin D levels between study groups at the baseline. In total, $60 \%$ and $40 \%$ of study subjects had deficiency (less than $20 \mathrm{ng} / \mathrm{ml}$ ) and insufficiency (20-29 ng/ml) vitamin $\mathrm{D}$, respectively.

The results of ANOVA ar baseline revealed no statistical significant difference between the serum hs-CRP $(\mathrm{F}=0.123, \mathrm{P}=0.946)$ and $\mathrm{TSH}(\mathrm{F}=0.031, \mathrm{P}=0.993)$ levels and body weight $(\mathrm{F}=0.715, \mathrm{P}=0.445)$. Also, significant changes were observed in the mean values of the hs-CRP and TSH levels in pre-/post-test stages. After eight weeks, Pilates training, vitamin $\mathrm{D}$, and combined groups showed a significant decrease in the hs-CRP and TSH levels and body weight (Table 2).

As shown in Table 3, in the between-group analysis, the hs-CRP and TSH levels and body weight were significantly lower in the intervention groups than in the control group. The combined intervention was associated with a stronger effect on reducing hs-CRP and TSH levels compared to Pilates training and vitamin D supplementation, and also weight loss compared to the vitamin D supplementation. Also, the effect of Pilates training on weight loss was significantly greater than vitamin D supplementation.

\section{Discussion}

In the present study, the effect of regular Pilates exercises with vitamin D intake on TSH and hs-CRP levels in overweight men was investigated. Our results showed an unfavorable vitamin D status so that $40 \%$ of the subjects had insufficient levels of vitamin D and $60 \%$ had a vitamin D deficiency. Also, eight weeks of Pilates training, vitamin D intake, as well as the combination intervention reduced hs-CRP and TSH levels, implicating that the non-pharmacological intervention of the present study can improve thyroid function and systemic inflammation in overweight men who did not have normal vitamin D status. Moreover, the combined intervention was associated with a stronger effect on reducing hs-CRP and TSH compared to the other two interventions, which indicates the synergistic effects of vitamin D and Pilates training. Bensal et al. [6] found that TSH levels in treated hypothyroid male patients decreased after three months of moderate-intensity regular exercise. However, Onsori and Galedari [14] found no significant changes in TSH levels in inactive middle-aged obese women after eight weeks of moderate-intensity aerobic exercise (50\%-70\% of maximum heart rate).

Mehravar et al. [13] also reported that eight weeks of Pilates training had no effect on TSH levels in inactive wom-

Table 1. Baseline anthropometric characteristics of the subjects

\begin{tabular}{|c|c|c|c|c|}
\hline \multirow{2}{*}{ Variables } & \multicolumn{4}{|c|}{ Mean $\pm S D$} \\
\hline & Pilates training & Vitamin D & Pilates training+vitamin D & Control \\
\hline Age $(y)$ & $48.92 \pm 3.58$ & $49.50 \pm 2.37$ & $49.00 \pm 3.32$ & $49.58 \pm 2.84$ \\
\hline Height (cm) & $181.42 \pm 3.58$ & $18.08 \pm 7.30$ & $179.77 \pm 1.64$ & $180.08 \pm 2.94$ \\
\hline $\mathrm{BMI}\left(\mathrm{kg} / \mathrm{m}^{2}\right)$ & $28.39 \pm 0.87$ & $28.42 \pm 1.01$ & $28.50 \pm 1.04$ & $28.33 \pm 0.61$ \\
\hline 25(OH)D (ng/ml) level & $17.5 \pm 6.24$ & $18.00 \pm 4.65$ & $17.61 \pm 4.61$ & $17.75 \pm 4.51$ \\
\hline
\end{tabular}


(Previous Title: The Journal of Oazvin University of Medical Sciences)

Table 2. Comparison of the mean changes between groups at baseline and after eight weeks

\begin{tabular}{|c|c|c|c|c|c|c|}
\hline \multirow{2}{*}{ Variables } & \multirow{2}{*}{ Groups } & \multicolumn{3}{|c|}{ Mean \pm SD } & \multirow{2}{*}{ Effect Size } & \multirow{2}{*}{ P* } \\
\hline & & Pre-test & Post-test & Percentage of Changes (\%) & & \\
\hline \multirow{5}{*}{$\begin{array}{l}\text { hs-CRP } \\
(\mathrm{mg} / \mathrm{l})\end{array}$} & Pilates training & $1.99 \pm 0.41$ & $1.58 \pm 0.32$ & $-19.90 \pm 4.42$ & $0.487($ Small) & $<0.001$ \\
\hline & Vitamin D & $1.93 \pm 0.34$ & $1.65 \pm 0.28$ & $-14.92 \pm 3.42$ & 0.409(Small) & $<0.001$ \\
\hline & $\begin{array}{l}\text { Pilates training } \\
\text { +vitamin }\end{array}$ & $1.91 \pm 0.38$ & $1.34 \pm 0.20$ & $-30.21 \pm 3.29$ & 0.648(Moderate) & $<0.001$ \\
\hline & Control & $1.97 \pm 0.32$ & $1.98 \pm 0.31$ & $0.17 \pm 1.24$ & 0.015 (Small) & 0.727 \\
\hline & & & $F=178.706$ & $P<0.001$ & & \\
\hline \multirow{4}{*}{$\begin{array}{c}\text { TSH } \\
(\mu \mathrm{U} / \mathrm{ml})\end{array}$} & Pilates training & $3.17 \pm 0.97$ & $2.44 \pm 0.81$ & $-23.32 \pm 3.51$ & $0.378($ Small) & $<0.001$ \\
\hline & Vitamin D & $3.08 \pm 0.82$ & $2.48 \pm 0.74$ & $-19.78 \pm 3.43$ & 0.358(Small) & $<0.001$ \\
\hline & $\begin{array}{l}\text { Pilates training } \\
\text { +vitamin }\end{array}$ & $3.15 \pm 0.87$ & $2.09 \pm 0.59$ & $-32.47 \pm 3.18$ & 0.580(Moderate) & $<0.001$ \\
\hline & Control & $3.08 \pm 0.91$ & $3.10 \pm 0.89$ & $1.09 \pm 1.74$ & 0.011 (Small) & 0.137 \\
\hline \multirow{6}{*}{$\begin{array}{c}\text { Body } \\
\text { Weight } \\
\text { (Kg) }\end{array}$} & & & $F=66.280$ & $P<0.001$ & & \\
\hline & Pilates training & $93.41 \pm 2.78$ & $88.5 \pm 2.91$ & $-5.27 \pm 0.76$ & 0.691(Moderate) & $<0.001$ \\
\hline & vitamin D & $92.93 \pm 3.12$ & $91.92 \pm 2.33$ & $-1.08 \pm 0.73$ & 0.180 (Small) & $<0.001$ \\
\hline & $\begin{array}{l}\text { Pilates training } \\
\text { +vitamin }\end{array}$ & $92.31 \pm 4.07$ & $87.08 \pm 3.64$ & $-5.50 \pm 0.66$ & 0.561 (Small) & $<0.001$ \\
\hline & Control & $91.92 \pm 3.55$ & $92.29 \pm 3.86$ & $-0.77 \pm 0.43$ & 0.049(Small) & 0.137 \\
\hline & & & $F=6.926$ & $P<0.001$ & & \\
\hline
\end{tabular}

en with an average age of 25-40 years and normal BMI, which may be due to different subjects' BMI, TSH levels, and vitamin D status at baseline. However, the subjects in the present study had no sufficient vitamin D levels. In addition, Solanki et al. [15] found that people with higher BMI had higher TSH levels, and this trend continued from low weight to obesity. Other studies have shown a significant positive correlation between BMI and TSH in children with primary hypothyroidism treated with levothyroxine [19], a higher prevalence of subclinical hypothyroidism, and high TSH levels in people with a BMI higher than $29 \mathrm{~kg} /$ $\mathrm{m}^{2}$ [20]. Therefore, it seems that weight loss can be one of the possible mechanisms of the effect of Pilates exercise on reducing TSH, which increases with the use of vitamin D. The presence of TSH receptors in adipose tissue causes adipose tissue to proliferate and differentiate preadipocytes

Table 3. Results of Tukey test to compare the percentage of changes (\%) of the means

\begin{tabular}{|c|c|c|c|c|}
\hline \multicolumn{2}{|c|}{ Groups } & \multirow{2}{*}{$\begin{array}{l}\text { hs-CRP } \\
P<0.001\end{array}$} & \multirow{2}{*}{$\begin{array}{c}\text { TSH } \\
P<0.001\end{array}$} & \multirow{2}{*}{$\begin{array}{c}\text { Body Weight } \\
\text { P<0.001 }\end{array}$} \\
\hline & Pilates & & & \\
\hline \multirow[t]{2}{*}{ Control } & Vitamin D & $P<0.001$ & $P<0.001$ & $P=0.002$ \\
\hline & Pilates+vitamin & $P<0.001$ & $P<0.001$ & $P<0.001$ \\
\hline \multirow{2}{*}{ Pilates trainin } & Vitamin D & $P=0.002$ & $P=0.325$ & $P=0.327$ \\
\hline & Pilates+vitamin & $P<0.001$ & $P<0.001$ & $P=0.663$ \\
\hline Vitamin D & Pilates+vitamin & $P<0.001$ & $P<0.001$ & $P<0.001$ \\
\hline
\end{tabular}


into adipocytes. It is well established that TSH receptors in adipose tissue cause the proliferation of this tissue and the differentiation of preadipocytes into adipocytes [21]. Vitamin D modulates pituitary TSH secretion of thyrotropin by binding to specific binding sites, and exogenous vitamin D suppression suppresses pituitary TSH secretion of basal pituitary TSH [22]. Furthermore, an inverse relationship between the serum vitamin D level and TSH in euthyroid adults and patients with nonspecific symptoms of tiredness was confirmed in several studies [23].

Based on these results, it seems that the improvement in vitamin $\mathrm{D}$ levels resulting from these interventions may be one of the possible reasons for the decrease in TSH levels in overweight men in the present study. This is in line with an earlier report showing that vitamin D intake $(50,000$ units per week) for 12 weeks decreased serum TSH levels in hypothyroid patients [24]. Simsek et al. [25] in their study on patients with autoimmune thyroid diseases, found that an oral dose of $1000 \mathrm{IU}$ vitamin D3 per day for one month had no effect on serum TSH, which may be due to the short period of vitamin D intake. Training-induced increase in metabolic activity and burning more calories Are effective to lose weight and improve thyroid function [6]. A decrease in dopamine receptors in the brain due to obesity leads to the release of TSH secretion in obese people, and up-regulation of dopamine due to weight loss normalizes TSH secretion obesity [26].

Moreover, our findings demonstrated that vitamin D supplementation, Pilates exercises, and a combination of the two interventions caused a decrease in hs-CRP levels and body weight. These findings were almost concordant with previous studies indicating that eight weeks of Pilates training decreased CRP level, body fat percentage, and weight in obese and/or overweight women [27, 28]. Although the mechanisms underlying the effect of exercise on CRP have not been fully elucidated, some plausible mechanisms have been proposed. Physical activity can reduce the production of cytokines in adipose tissue, muscles, and mononuclear cells and improve insulin sensitivity, endothelial function, and weight loss, which all lead to a reduction in CRP. Adipose tissue is the major source of TNF- $\alpha$ and IL- 6 , and exercise can reduce the release of proinflammatory cytokines and down-regulate CRP through the reduction in adipose tissue and suppressing sympathetic stimulation [26].

An inverse association between the levels of 25-hydroxyvitamin D and CRP in patients with inflammatory and non-inflammatory diseases [29] and a positive association between serum TSH and IL-6 and CRP in subclinical hypothyroid patients have been reported [30]. Also,
Khodadoust and Habibian reported that both vitamin D and exercise have an anti-inflammatory effect and can lead to a reduction in TNF- $\alpha$ levels in overweight men with abnormal vitamin D status [18]. Therefore, it seems that there is a tripartite relationship between vitamin D status, systemic inflammation, and thyroid hormone function in obese and/or overweight conditions, which can be affected by exercise and vitamin D supplementation.

The present study was associated with some limitations, such as the small number of subjects and no measurement of the time spent during Sunlight Peak in the study population. Therefore, further studies with a larger number of subjects are needed to confirm the possible mechanisms of the effect of Pilates training and vitamin D intake on thyroid function and an inflammatory index of CRP.

\section{Conclusion}

The results showed a high prevalence of vitamin D deficiency and/or insufficiency in overweight middle-aged men. Vitamin D intake, Pilates training, and the combined intervention can improve thyroid function and systemic inflammation in overweight men with abnormal vitamin D status. However, combined intervention is associated with stronger effects. Therefore, maintaining a vitamin D status at normal levels and performing regular physical activities to increase body health are recommended for overweight people.

\section{Ethical Considerations}

\section{Compliance with ethical guidelines}

This paper was approved by the Islamic Azad University, Babol Branch, (Code: IR.IAU.BABOL. REC.1398.088).

\section{Funding}

This article was not supported and was derived from the master's thesis of the first author, Sports Physiology student at Islamic Azad University, Qaemshahr Branch.

\section{Authors' contributions}

All authors equally contributed to preparing this article.

\section{Conflict of interest}

The authors declared no conflicts of interest. 


\section{References}

[1] Stępień M, Stępień A, Wlazeł RN, Paradowski M, Banach $\mathrm{M}$, Rysz J. Obesity indices and inflammatory markers in obese non-diabetic normol and hypertensive patients: A comparative pilot study. Lipids Health Dis. 2014; 13(1):29. [DOI:10.1186/1476-511X-13-29] [PMID] [PMCID]

[2] Mraović T, Radaković S, Medić DR, Dinčić D, Ostojić VT, Čairović $\mathrm{A}$, et al. The relationship between adiposity parameters and C-reactive protein values in overweight and obese women. Vojnosanit Pregl. 2018; 75(2):185-90. [DOI:10.2298/ VSP160419208M]

[3] Kim D. The role of vitamin D in thyroid diseases. Int J Mol Sci. 2017; 18(1949):1-19. [DOI:10.3390/ijms18091949] [PMID] [PMCID]

[4] Barchetta I, Baroni MG, Leonetti F, De Bernardinis M, Bertoccini L, Fontana M, et al. TSH levels are associated with vitamin D status and seasonality in an adult population of euthyroid adults. Clin Exp Med. 2015; 15(3):389-96. [DOI:10.1007/ s10238-014-0290-9] [PMID]

[5] Gupta G, Sharma P, Kumar P, Gappa M, Sharma R. A Correlation between thyroid stimulating hormone and body mass index women with subclinical hypothyroidism. Asian J Pharm Clin Res. 2015; 8(4):206-8. https://innovareacademics.info/ journals/index.php/ajpcr/article/download/6410/2717

[6] Bansal A, Kaushik A, Singh CM, Sharma V, Singh H. The effect of regular physical exercise on the thyroid function of treated hypothyroid patients: An interventional study at a tertiary care center in Bastar region of India. Arch Med Health Sci. 2015; 3:244-6. [DOI:10.4103/2321-4848.171913]

[7] Mackawy AM, Al-Ayed BM, Al-Rashidi BM. Vitamin d deficiency and its association with thyroid disease. Int J Health Sci (Qassim). 2013; 7(3):267-75. [DOI:10.12816/0006054] [PMID] [PMCID]

[8] Yarparvar A, Elmadfa I, Djazayery A, Abdollahi Z, Salehi F. The association of vitamin $d$ status with lipid profile and inflammation biomarkers in healthy adolescents. Nutrients. 2020; 12(2):590. [DOI:10.3390/nu12020590] [PMID] [PMCID]

[9] de Oliveira C, Biddulph JP, Hirani V, Schneider IJC. Vitamin D and inflammatory markers: cross-sectional analyses using data from the English Longitudinal Study of Ageing (ELSA). J Nutr Sci. 2017; 6:e1. [DOI:10.1017/jns.2016.37] [PMID] [PMCID]

[10] Liefaard MC, Ligthart S, Vitezova A, Hofman A, Uitterlinden AG, Kiefte-de Jong JC, et al. Vitamin D and C-reactive protein: A mendelian randomization study PLoS One. 2015;10(7):e0131740. [DOI:10.1371/journal.pone.0131740] [PMID] [PMCID]

[11] Lavanya K, Ramamoorthi K, Acharya RV, Madhyastha SP. Association between overweight, obesity in relation to serum hs-CRP levels in adults 20-70 years. J Clin Diagn Res. 2017; 11(12):OC32-35. [DOI:10.7860/JCDR/2017/32422.11005]

[12] Fedewa MV, Hathaway ED, Ward-Ritacco C. Effect of exercise training on $\mathrm{C}$ reactive protein: a systematic review and meta-analysis of randomized and non-randomized controlled trials. BMJ. 2017; 51(8):10. [DOI:10.1136/bjsports-2016-095999] [PMID]

[13] Mehravar MR. The effect of eight-week Pilates exercise on the thyroid function in sedentary women. J Physic Act Horm 2018; 2(2):29-42. http://jpah.iaushiraz.ac.ir/article_542454_ cf80ecc0574b3c3ad234989b123f7710.pdf
[14] Onsori M, Galedari M. Effects of 12 weeks aerobic exercise on plasma level of TSH and thyroid hormones in sedentary women. Eur J Sport Sci Eur J Sport Sci. 2015; 4(1):45-9. https://www.researchgate.net/profile/Mohammad-Galedari-2/publication/319591512

[15] Solanki A, Bansal S, Jindal S, Saxena V, Shukla US. Relationship of serum thyroid stimulating hormone with body mass index in healthy adults. Indian J Endocrinol Metab. 2013; 17(Suppl 1):S167-9. [DOI:10.4103/2230-8210.119560] [PMID] [PMCID]

[16] Manji N, Boelaert K, Sheppard MC, Holder RL, Gough SC, Franklyn JA. Lack of association between serum TSH or free T4 and body mass index in euthyroid subjects. Clin Endocrinol. 2006; 64:125-8. [DOI:10.1111/j.1365-2265.2006.02433.x] [PMID]

[17] Chaudhary S, Dutta D, Kumar M, Saha S, Mondal SA Kumar A, et al. Vitamin D supplementation reduces thyroid peroxidase antibody levels in patients with autoimmune thyroid disease: An open-labeled randomized controlled trial. Indian J Endocrinol Metab. 2016; 20:391-8. [DOI:10.4103/22308210.179997] [PMID] [PMCID]

[18] Khodadost M, Habibian M. Investigating the changes of tumor necrosis factor-A and interleukin-10 after 8 weeks of regular pilates exercise and vitamin $\mathrm{D}$ intake in overweight men: A randomized clinical trial. J Arak Uni Med Sci. 2020; 23(6):888-901. [DOI:10.32598/jams.23.6.3537.5]

[19] Shaoba A, Basu S, Mantis S, Minutti C. Serum thyroidstimulating hormone levels and body mass index percentiles in children with primary hypothyroidism on levothyroxine replacement. J Clin Res Pediatr Endocrinol. 2017; 9(4):337-43. [DOI:10.4274/jcrpe.3661] [PMID] [PMCID]

[20] Sami A, Iftekhar MF, Rauf MA, Sher A. Subclinical Hypothyroidism among local adult obese population. Pak J Med Sci. 2018; 34(4):980-83. [DOI:10.12669/pjms.344.14127] [PMID] [PMCID]

[21] Vyakaranam S, Kondaveedu S, Nori S, Dandge S, Bhongir AV. Study of serum high-sensitivity c-reactive protein in subclinical hypothyroidism. Indian J Med Biochem. 2018; 22(1):66-70. [DOI:10.5005/jp-journals-10054-0057]

[22] Zhang Q, Wang Z, Sun M, Cao M, Zhu Z, Fu Q, et al. Association of high vitamin $d$ status with low circulating thyroidstimulating hormone independent of thyroid hormone levels in middle-aged and elderly males. Int J Endocrinol. 2014; 2014:631819. [DOI:10.1155/2014/631819] [PMID] [PMCID]

[23] Das G, Taylor PN, Javaid H, Tennant BP, Geen J, Aldridge A, et al. Seasonal variation of vitamin $\mathrm{D}$ and serum thyrotropin levels and its relationship in euthyroid cau casian population. Endocr Pract. 2018; 24(1):53-9. [DOI:10.4158/EP-2017-0058] [PMID]

[24] Talaei A, Ghorbani F, Asemi Z. The effects of vitamin D supplementation on thyroid function in hypothyroid patients: a randomized, double-blind, placebo-controlled trial. Indian J Endocrinol Metab. 2018; 22(5):584-88. [DOI:10.4103/ ijem.IJEM_603_17] [PMID] [PMCID]

[25] Simsek Y, Cakir I, Yetmis M, Dizdar OS, Baspinar O, Gokay F. Effects of vitamin D treatment on thyroid autoimmunity. J Res Med Sci. 2016; 21:85. [DOI:10.4103/1735-1995.192501] [PMID] [PMCID]

[26] Baharloo S, Taghian F, Hedayati M. [Effects of aerobic exercise on C-reactive protein and lipid profile in subclinical hypothyroidism among overweight-obese women (Persian)] 
Modares J Med Sci (Pathobiology). 2014; 17(1):91-102. http:// mjms.modares.ac.ir/article-30-718-en.html

[27] Atashak S. The effect of eight weeks of Pilates training on C-reactive protein, insulin resistance, and body composition in middle-aged obese women. JRUMS. 2018; 17(5):421-34. http://journal.rums.ac.ir/article-1-3997-en.html

[28] Seyfi E, Alijani M, Baghaiee B. [Investigating the effect of eight weeks of pilates training in combination with probiotic supplementation on some inflammatory markers in overweight women (Persian)]. Complement Med J Fac Nurs Midwifery. 2018; 8(1):2153-66. https:/ / www.semanticscholar.org/ paper/Investigating-the-Effect-of-Eight-Weeks-of-Pilates-Alijani-Seyfi/d9d4fa9c0c9b013aba4099e19c2502079dfc88bc

[29] Mala S, Kumar S, Piryanka K, Shaikh ZA. Serum inflammatory markers in subclinical hypothyroidism. Eur J Pharm Med Res. 2017; 4(9):855-9. https://www.researchgate.net/ profile/Sateesh-Kumar-15/publication/338867857

[30] Kruit A, Zanen P. The association between vitamin D and C-reactive protein levels in patients with inflammatory and non-inflammatory diseases. Clin Biochem. 2016; 49(7-8):534-7. [DOI:10.1016/j.clinbiochem.2016.01.002] [PMID] 